\title{
Distance Learning at the Medical Faculty of University of Sarajevo
}

\author{
Izet Masic ${ }^{1}$, Ahmed Novo' ${ }^{1}$, Zlatan Masic ${ }^{1}$ \\ 1. Faculty of Medicine, University of Sarajevo, Bosnia and Herzegovina
}

Summary: Possibilities of introduction of distance learning in medical curriculum are the title of project which has been realizing at Department of Medical Informatics, Medical Faculty since year 2002. The Project is approved by Federal and Cantonal ministries of science and education. The purpose of this project is to support improvement educational process at biomedical faculties using contemporary methods, methodologies and information technologies in accordance with strategy and objectives given by Bologna declaration. The pilot project is realized during three years, the theoretical and practical parts of the subject Medical Informatics are adapted to modern concepts of education using world trends of distance learning. One group of students from the Medical Faculty was involved in this project, which was finalized by electronic registration of an exam and electronic testing on 20 June 2005, in public in the Physiological amphitheatre of the Medical faculty in Sarajevo. In this article we have given description of the project and phases of its realization, and basic adventages and disadvantages we have noticed so far.

Keywords: distance learning, biomedicine, medical curriculum

\section{Introduction}

The health sector is one of the most evident potential beneficiaries of the Internet revolution and World Wide Web resource in the present and in the future, when the tools now available and the system's reliability and efficacy as a whole will be further incremented and improved [1], [2], [3], [4].

- Low level of education in secondary schools is improving, but it is still low,

- shortage of modern equipment,

- lack of LAN, connection to Internet, organized web design,

- problem of the maintenance,

- free access to a computer room.

- Students are not informed about functioning of education and health systems in whole, especially at universities.

- All new measures and decisions must be formalized through legislation.

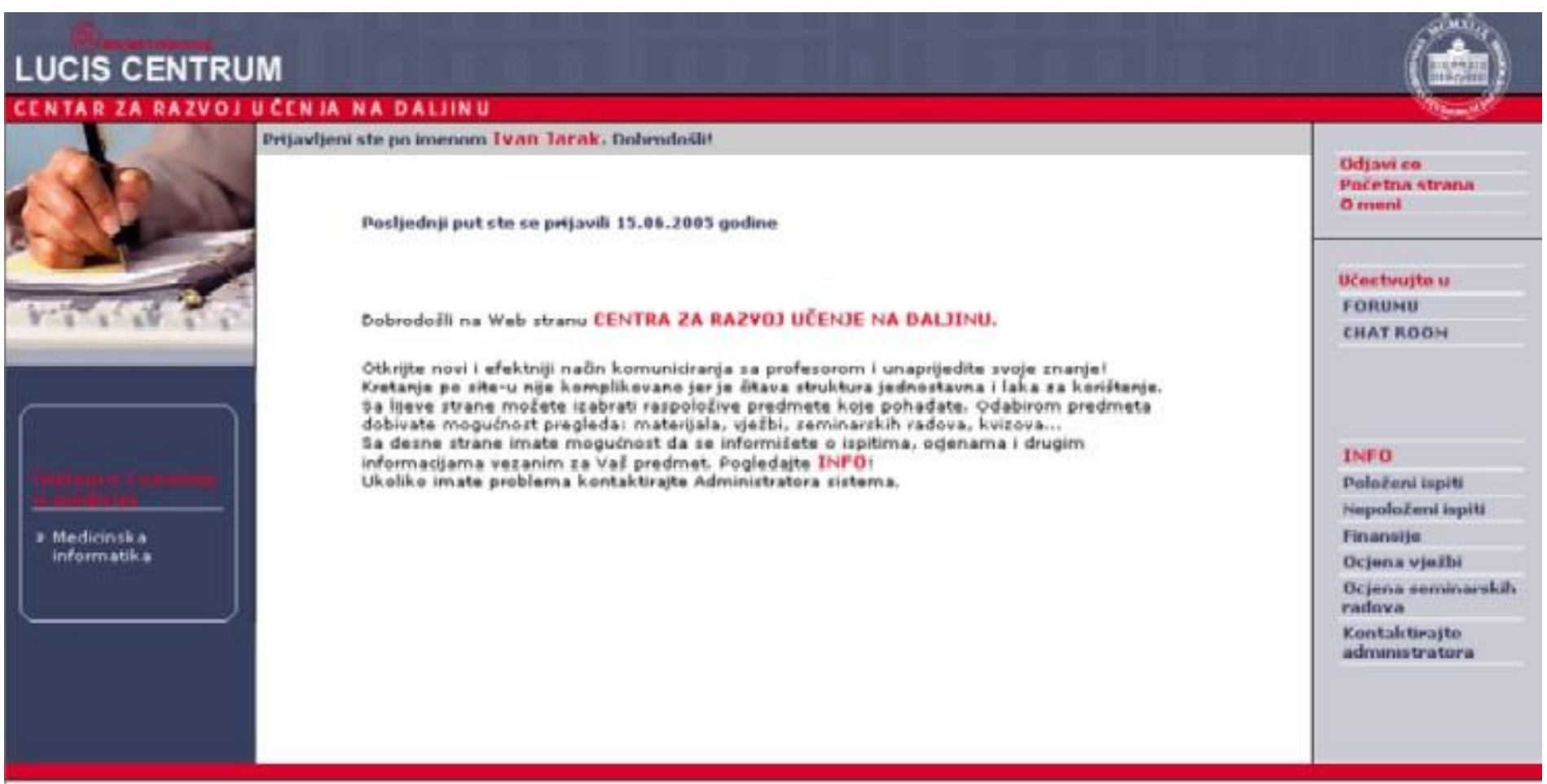

Fig. 1. Web site of University e-learning centre. 
In our system the power of knowledge should be prevailing, instead of the power of authorities.

Distance learning presents the type of education where a professor and a student communicate and learn from each other via an electronic system [5], [6], [7], [8]. Since distance learning takes us away from the traditional student-teacher "face to face" classroom learning, good educational system planning and organizing is a necessary new educational platform, necessary due to professor's atempts to convey his or her knowledge to students learning from a distance successfully [9], [10]. The platform for the course of distance learning is accomplished due to collaboration with UTIC. With their help the center for distance learning, "LUCIS CENTRUM", is created (Figure 1). We hope that this is just a beginning step towards improvemetns of the Bosnia-Herzegovinian education system and that this project will serve as an indicator towards the future [11], [12], [13], [14], [15], [16], [17].

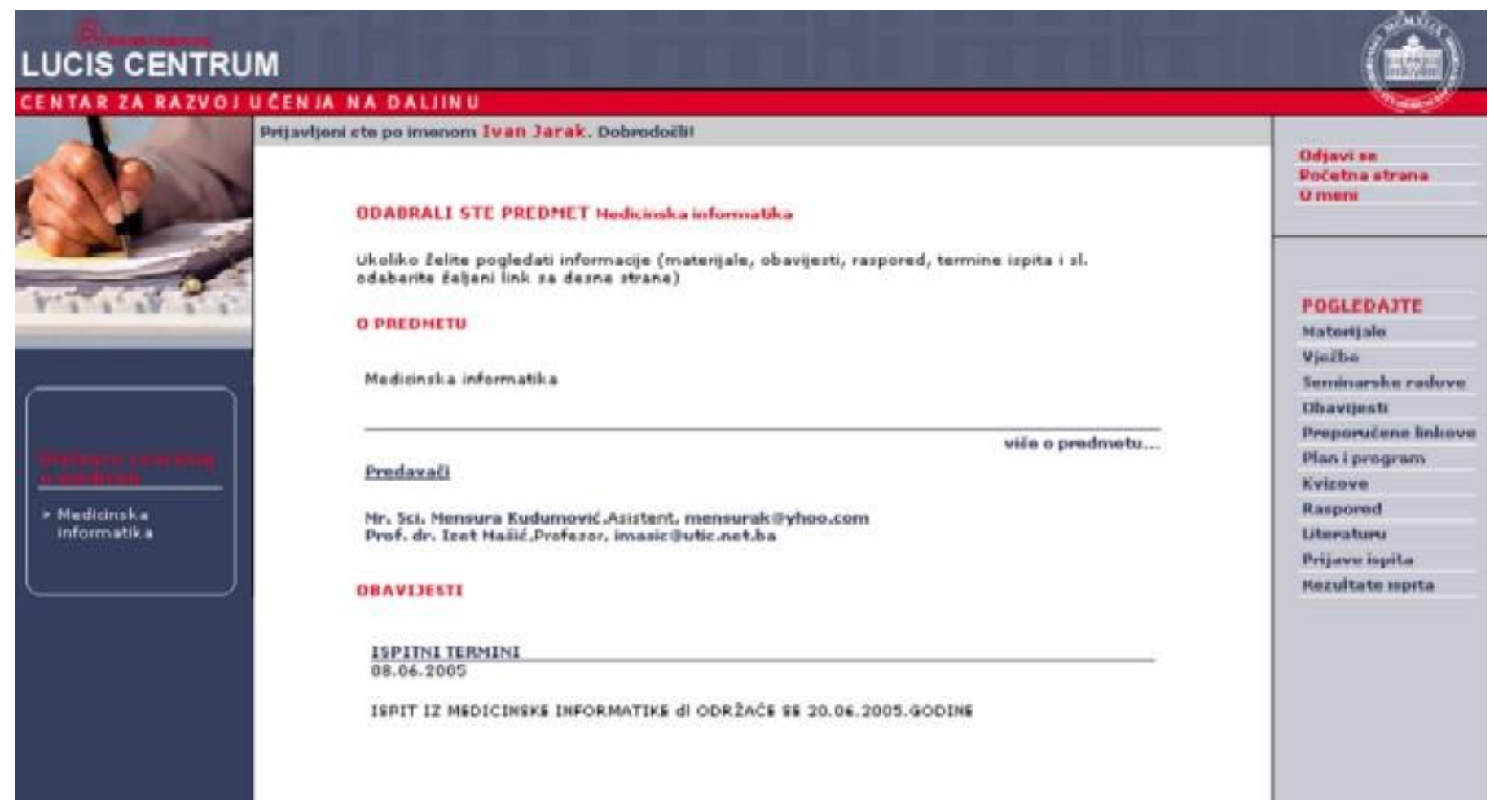

Fig. 2. Web site of University E-learning centre- Lucis Centrum/contents.

\section{Methods and contents of Distance learning education at the Medical Faculty of University of Sarajevo}

Lecture contents will be presented in our virtual classroom. In our case, learning materials from the subject of medical informatics, and later, hopefully from other medical subjects, will be available on the web site, www.e-learning.ba (Figure 2) and www.imasic.org/mi/.

In this "classroom", learning materials, power point lecture presentations as well as practice exercises with step-by-step instructions, are easily accessible to students. Moreover, on this web site, students will be able to find subject relating literature as well as the English version of the presentations.

\begin{tabular}{l}
\hline POGLEDAJTE \\
\hline Materijale \\
\hline Vježbe \\
\hline Seminarske radove \\
\hline Obavijesti \\
\hline Preporučene linkove \\
\hline Plan i program \\
\hline Kvizove \\
\hline Raspored \\
\hline Literaturu \\
\hline Prijave ispita \\
\hline Rezultate ispita \\
\hline
\end{tabular}

Fig. 3. Links of contents. 
To access this information requires only one click on a download option (Figure 3) as well as one second patience depending on student's Internet speed connection.

Shortly, our virtual classroom gives students the opportunity to access needed information, at any time, and in any place without having to be bound to the classroom.

A student is able to browse through the "classroom" using standard navigations (Figure 3). Using these simple navigations, maximal efficiency and fast access to needed materials is possible (Figure 4).

\begin{tabular}{l} 
Odaberite materijal \\
1. 10 od 31 \\
Introduction \\
Chapter 15. Healthcare information systems \\
Chapter. 14 Inforamation technologies in medicine and healthcare \\
Chapter 13. Computers in the education and researching \\
Chapter 12. Biomedical system of the scientific and expert information \\
Chapter 11. Computer support to the medical decision making \\
Chapter 10. Medical decision making \\
Chapter 9. Models, modeling and simulation by a computer \\
Chapter 8. Hardware and software \\
Chapter 7. Structure and organization od data \\
\hline
\end{tabular}

Fig. 4. Contents of medical informatics education (lectures units).

As we can see in the picture, all links are in an chronological order according to the plan and program of the lecture as well as practice. Special attention is given to the link "kvizovi."

In order for the student to check his/her progress (to test his/her knowledge of the lecture he/she studied), every lecture is followed by quizzes. Quiz questions are multiple choice questions (Figure 5) and they are based on the lecture content.

After every quiz, student receives the "feedback" regarding his/her progress. Results are given in terms percentages (one needs $51 \%$ to pass). This way students had total control over their work.

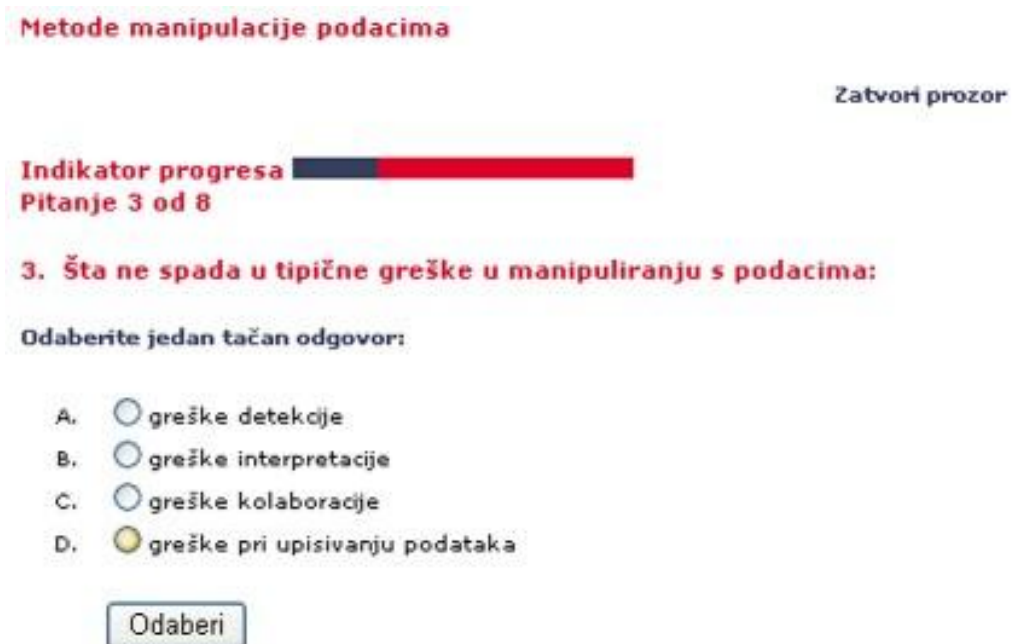

Fig. 5. Multiple choice quiz. 


\section{Advantages and disadvantages of Distance learning education}

Distance learning compared to the traditional way of learning have many its advantages as well as disadvantages [3], [6], [9], [12], [15], [16], [17]. Some of the main advantages of distance learning are: the economical factor; a student has 24 hour access to needed information; he/she is given the opportunity to learn the subject in his/hers own time and speed; he/she can access learning materials independently of a place or time; he/she is given the opportunity to learn how to work independently; using e-mail or chat rooms he/she is able to contact a professor or his/hers assistant if there are any questions or confusions regarding lectures; etc. Many critics consider that using e-mail or chat rooms to obtain a contact with the professor is actually the main disadvantage of this system of learning [1], [3], [13], [17]. A question arises whether this way of the professor-student communication is helpful to students as the face-to-face contact is missing as well as the opportunity of student-professor relationship building. However, in many universities across Bosnia and Herzegovina student's contact with a professor is almost impossible (unless one needs to take the exam orally), due to many professors having other jobs or responsibilities; students are mainly able to communicate with professor's assistants. Moreover, through the traditional way of teaching, during the lectures, students obtain from their professors mostly the information, which they can find in the literature or on the Internet. Rarely, there is a studentprofessor interaction or lecture discussion during the class. From this one can conclude that an ambitious student using teleeducation will experience minimum lose.

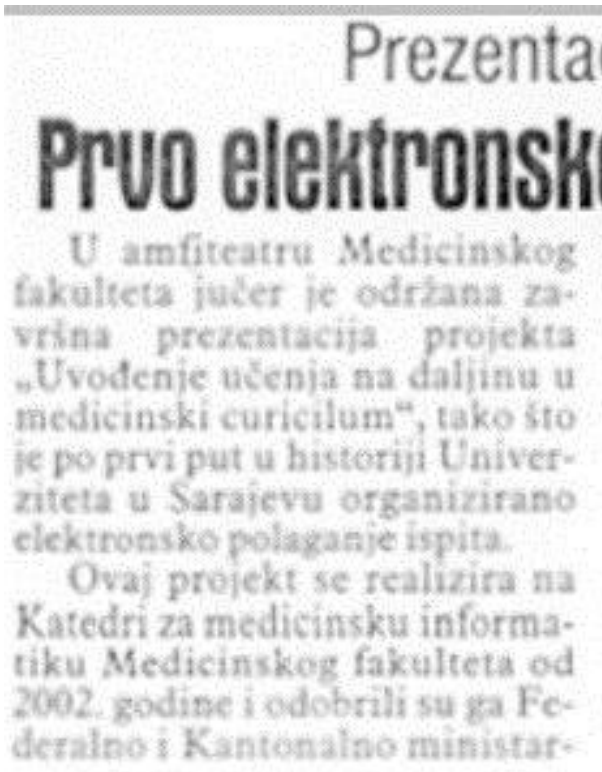

\section{Prezentacija na Medicinskom fakultetu}

\section{Pruo elektronsko polaganje ispita}

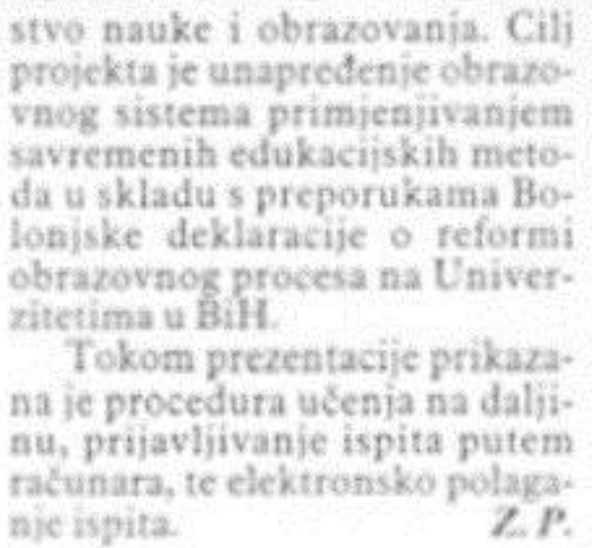

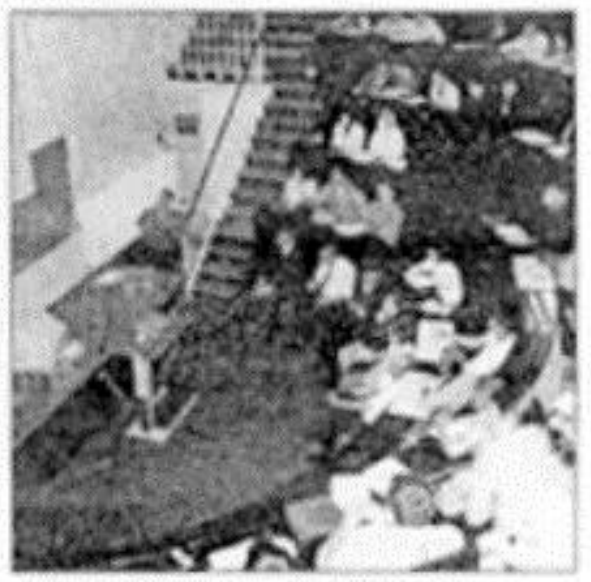

Prikazana procedura ucenia na dafining

Fig. 6. Public presentation of electronic exams at Medical Faculty of University of Sarajevo held in June 2005.

\section{Conclusion}

The rise of IT as an artefact of everyday life in the modern world has brought with it the dawn of a new era, often doubbed the "Age of Information". These technologies are changing the way we perceive the world, how we think and communicate with others. Established cultures are being transformed and new cultures are forming. New virtual environment affects the way we build our sense of who we are.

\section{Some characteristics of the Internet:}

- Large volume of users and potential users,

- lack of physical boundaries, which allows for the manipulation of time and space,

- information can be accessed in a concurrent fashion using different media,

- concept of redundancy.

In the virtual environment we are applying for information in a way that is expanding our senses and one must take into account that experience is occurring in the context of the virtual environment. Information without a context has no meaning.

\section{Expected outcomes of the project Introduction and Implementation of Distance learning in medicine are:}

- Development and integration of informatics-computer technologies in medical education,

- creation of flexible infrastructure which will enable access to e-Learning by all students and teaching staff,

- improvement of digital literacy of academic population,

- ensure high educational standards to students and teaching staff and

- to help medical staff to develop "Lifelong learning way of life". 
The health sector is one of the most evident potential beneficiaries of the Internet revolution and World Wide Web resource in the present and in the future, when the tools now available and the system's reliability and efficacy as a whole will be further incremented and improved.

- Low level of education in secondary schools is improving, but it is still low;

- shortage of modern equipment;

- lack of LAN, connection to Internet, organized web design;

- problem of the maintenance;

- free access to computer rooms;

- students are not informed about functioning of education and health systems in whole, especially at universities;

- all new measures and decisions must be formalized through legislation.

In our system the power of knowledge should be prevailing, instead of the power of authorities.

\section{References:}

[1] Mašić I, Novo A, Kudumović M, Mašić Z.: Edukacija iz Medicinske informatike na medicninskim fakultetima u BiH. AIM, 2005; $13(1): 3-8$.

[2] Masic I, Novo A, Kudumovic M, Masic Z.: E-learning at Medical Faculty of University of Sarajevo. AIM; 2005; 13(3): $132-5$.

Masic Z, Novo A, Masic I, Kudumovic M, Toromanovic S, Rama A, Dzananovic A, Bander I, Masic M, Guso E, Balta E.: Distance

[3] Learning at Biomedical Faculties in Bosnia and Herzegovina. Connecting Medical Informatics and Bio-Informatics. Procedings of MIE 2005 (editors: Engelbrecht R, Geissbuhler A, Lovis C, Mihalas G). IOS Press, 2005: 267-72.

[4] Mašić I, Bilalovic N, Karčić S, Kudumović M, Pašić E.: Telemedicine and telemetric in B\&H in the war and Post war Times. European Journal of Medical Research, 2002; 7 (supl.1): 47.

[5] Hasman A, Haux R.: Curricula in medical informatics. Stud Health Technol Inform. 2004;109:63-74.

[6] Mantas J.: Future trends in Health Informatics - theoretical and practical. Stud Health Technol Inform. 2004;109:114-27.

[7] Marques EP, Marin HF, Massad E, Fraser H, Ohno-Machado L.: Training in health informatics in Brazil. Stud Health Technol Inform. 2002;90:757-60.

[8] Recommendations of the International Medical Informatics Association (IMIA) on education in health and medical informatics. Methods Inf Med. 2000;39:267-77.

[9] Kern J.: Medical informatics in the medical curriculum--when? Stud Health Technol Inform. 1999;68:484-488.

[10] Kern J.: Medical Informatics Education - How to Tailor the Course to Given Stage of Student's Knowledge? AIM 2002;10(2):59-61.

[11] Masic I, Kudumovic M, Pasic E.: Education of Medical Informatics at Medical Faculty of Sarajevo. Med Arh, 2004; 58 (1, supl. 2): 8891.

[12] Mašić I, Kudumović M, Pašić E.: Deset godina edukacije iz Medicinske informatike na Medicinskom fakultetu u Sarajevu. Med Arh, 2002; 56 (4): 233-9.

[13] Šabanović Z, Mujčinagić A.: Edukacija medicinske informatike na Medicinskom fakultetu Tuzla. Med Arh 2004; 58 (1, supl.2): $92-94$.

[14] Mašić I, Novo A, Kudumović M.: Teleeducation at biomedical faculties in Bosnia \& Herzegovina, AlM 2004; 58 (3-4): 15-18.

[15] Mašić I, Riđanovic Z:: Edukacija iz medicinske informatike i njene perspektive, AIM, 2001; 9 (3-4): 59-60.

[16] Mašić I, Ramić-Čatak A, Kudumovic

[17] Ramić-Čatak A, Masic I.: Distance learning - ucenje s distance u medicinskoj edukaciji. AIM, 2002; 10 (2): $63-6$. 